\title{
Dinámicas periurbanas: reflexiones sobre la urbanización de la periferia huancána
}

\section{Periurban dynamics: reflections about the urbanization of Huancayo's periphery}

\section{INTRODUCCIÓN}

Las áreas de montaña representan sistemas socioambientales altamente sensibles. Como consecuencia reaccionan rápidamente a los efectos de la globalización y del calentamiento global (1). Las actividades sociales y económicas, sin duda, no están diseminadas homogéneamente. Se concentran cada vez más alrededor de los centros urbanos de los valles principales (2-3) e impulsan el crecimiento urbano a lo largo de ejes de desarrollo. Ante el cambio global de carácter ecológico y social (4) - se está cambiando la estructura del espacio periurbano, generando nuevos desafíos para la relación entre el hombre y e medio ambiente. Las siguientes reflexiones intentan sintetizar e interpretar selectos aspectos de las dinámicas periurbanas en el contexto de la ciudad de Huancayo.

\section{Ejes de crecimiento y estructura periférica}

Las zonas periurbanas se caracterizan por ser una dinámica interfaz entre "la ciudad" y "el campo", representada por los cambios continuos del uso de suelo. En el caso del crecimiento urbano de Huancayo, el aumento poblacional es una de las fuerzas motrices.

La población del distrito de El Tambo creció casi el 150 por ciento en el periodo 1981-2007, y superó la cifra poblacional del distrito central de Huancayo -que creció solamente 25 por ciento durante la misma época- a inicios de los años 90. Al igual que en la

1 BSc en Geografía, MSc en Geografía con mención en investigación urbana y regional, estudiante de PhD por el Instituto de Geografía de la Universidad de Innsbruck, Austria 


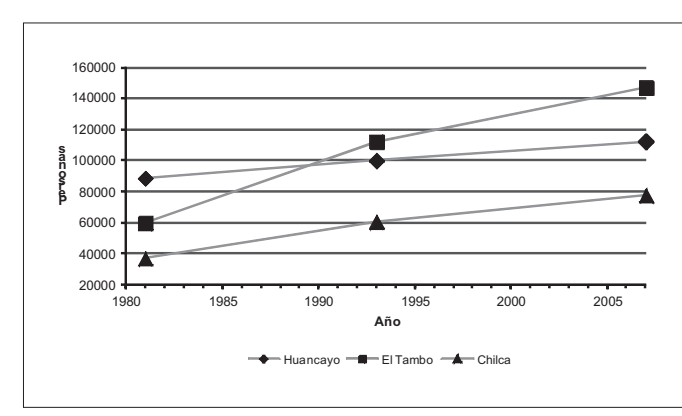

Figura 1. Desarrollo poblacional en distritos de la aglomeración de Huancayo 1981-2007.

Fuente: Instituto Nacional de Estadística e Informática 1981,1993, 2007.

periferia del norte, la ciudad se expandió hacia el sur de Huancayo, donde la población de Chilca se duplicó [5-6]. Actualmente, la inicial periferia de El Tambo alberga numerosas infraestructuras de importancia regional: el estadio Mariscal Castilla, el terminal terrestre, el hospital Essalud, la Universidad Nacional del Centro del Perú, parques industriales y —últimamente - también sucursales de cadenas de retail. En suma se puede observar una zona heterogénea a lo largo de la periferia del eje norte-sur, que se orienta a las grandes vías de transporte (linea ferroviaria carretera principal), donde se encuentran diversos usos residenciales, comerciales, industriales y públicos.

Desde la última década se está concretizando el desarrollo de un nuevo eje periurbano este-oeste: por un lado a lo largo del valle del Río Shullcas (San Carlos, San Antonio y Chorrillos), y por el otro lado a lo largo del Río Cunas (Pilcomayo). Ambas zonas destacan por su carácter ruralurbano, contando tanto con amplias zonas recreacionales y áreas agrícolas, como con elementos urbanos que recuerdan a las zonas residenciales de las megaciudades andinas [7]. Son áreas residenciales de carácter privado, albergando sedes principales y filiales regionales de universidades, colegios y clínicas de manejo privado. Por esa razón no se los puede clasificar netamente como clásicas áreas suburbanas, las cuales son caracterizadas principalmente por su monofuncionalidad residencial y la dependencia esencial del centro urbano. Se aproximan más a los paisajes postsuburbanos — si bien a pequeña escala - los cuales se vuelven independiente del centro urbano, e incluso empiezan a competir con él. La comparación de las denominaciones de selectos proyectos imobiliarios privados en el eje de desarrollo este-oeste podría explicar los motivos de la urbanización de esta parte de la periferia de Huancayo.
La gran mayoría de los proyectos selectos usa nombres ("Natura", "Pradera", "Retamos") que quieren promover una connotación medioambiental: naturaleza, limpieza y salud funcionan como factores de atracción de esta periferia florida ("Primavera"). Un condominio promovido fue denominado "La Fortaleza", sugeriendo seguridad ciudadana - żuién no quisiera vivir en una fortaleza florida rodeada por praderas?

Tabla1. Selectos proyectos inmobiliarios promovidos en la periferia de Huancayo.

\begin{tabular}{ll}
\hline Denominación & Ubicación \\
\hline Primavera & Pilcomayo \\
La Fortaleza & Pilcomayo \\
Villa Natura & Pilcomayo \\
Del Prado & San Carlos, San Antonio, Chorrillos \\
La Pradera & San Carlos, San Antonio, Chorrillos \\
Retamos de San Luís & San Carlos, San Antonio, Chorrillos \\
\hline
\end{tabular}

\section{CONCLUSIÓN}

Las pasadas reflexiones intentaron ordenar y sintetizar selectos aspectos de la urbanización en la periferia de Huancayo. Fueron atestados dos ejes de expansión urbana. Hacia el norte y el sur se encuentran zonas de carácter más espontáneo y de uso muy heterogéneo. Orientado al este y oeste predominan las nuevas zonas ruralurbanas con alto valor recreativo, mayoritariamente residenciales de carácter planeado, que se dirígen a una clientela económicamente potente en busca de calidad ambiental y seguridad. Queda aún como tarea poner los fenómenos mencionados en contexto con el cambio global. ¿Cuáles son las peculiaridades de dichos procesos en las áreas de montaña y qué desafíos generan?

Suponiendo que la expansión urbana en la periferia de Huancayo sigue aumentando, se agravarían los problemas causados por el cambio global: no solamente por la más alta densidad de población y bienes, sino sobre todo por las crecientes disparidades socioespaciales. Por ejemplo, ante la deglaciación del Huaytapallana - primera fuente de agua potable de Huancayo- habría problemas de abastecimiento de agua [8], lo que crearía problemas en los sectores económicos de agricultura, industria y turismo. Además, la creciente segregación y fragmentación social en 
Huancayo aumentaría el número de la población de bajos recursos económicos vulnerable a la escasez de agua potable, lo que a su vez produciría nuevos conflictos sociales. La elaboración de estrategias para el desarrollo sostenible de las ciudades andinas requiere la cooperación transdisciplinaria, incorporando tanto las diversas disciplinas científicas, como a los planificadores, los políticos y la población.

\section{REFERENCIAS BIBLIOGRAFCAS}

1. Borsdorf A, Braun V. The European and Global Dimension of Mountain. Research -An Overview. Revue de Géographie Alpine. 2008; 96 (4): 117-29.

2. González Urruela E. La evolución de los estudios sobre áreas periurbanas. Anales de Geografía de la Universidad Complutense. 1987; 7: 439-48.

3. Bertrand N, Vanpeene-Bruhier S. Les paysages périurbains montagnards à la croisée des regards des sciences écologiques et des sciences socio-économiques. Revue de Géographie Alpine. 2007; 95(4): 57-68.

4. Bebbington A. Globalized Andes? Livelihoods, Landscapes and Development. Cultural Geographies. 2001 ; 8(4): 414-36

5. Instituto Nacional de Estadística e Informática. Censos Nacionales 1981: VIII de Población y III de Vivienda. Lima: INEI; 1981.

6. Instituto Nacional de Estadística e Informática. Censos Nacionales 2007: XI de Población y VI de Vivienda. Lima: INEI; 2007.

7. Borsdorf A, Hidalgo R. New dimensions of social exclusion in Latin America: From gated communities to gated cities, the case of Santiago de Chile. Land Use Policy. 2008; 25: 153-60

8. Martínez A, Takahashi K. Vulnerability and adaptation to climate change in Central Peruvian Andes cities. En: Laband DN, editor: Proceedings of the conference "Emerging Issues Along Urban/Rural Interfaces: Linking Science and Society"; 2005 : Atlanta, GA, 2005. p. 306-8.

Correo electrónico:

andreas.o.haller@student.vibk.ac.at 